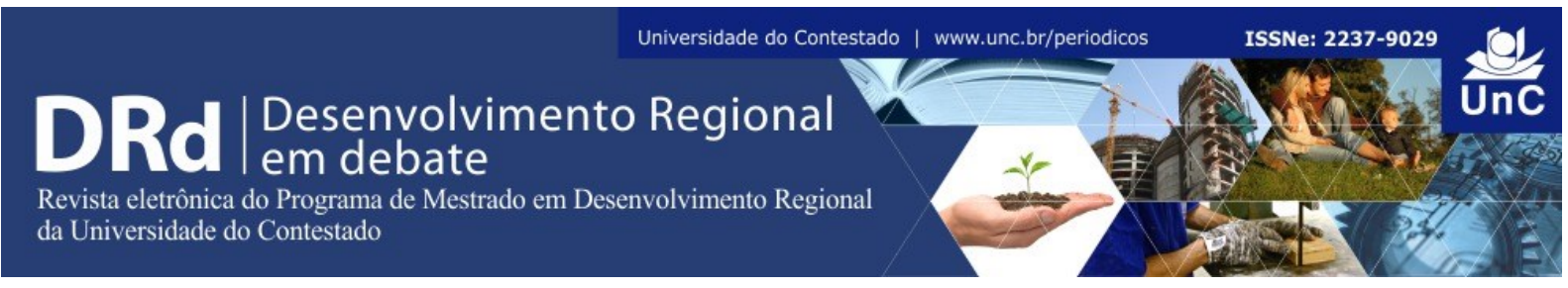

\title{
A TECNOLOGIA DE INFORMAÇÃO E COMUNICAÇÃO COMO MECANISMO PARA A MIGRAÇÃO: UM ESTUDO SOBRE OS HAITIANOS NO BRASIL
}

\author{
Beatriz Leite Gustmann de Castro ${ }^{1}$ \\ Maria de Lourdes Bernartt ${ }^{2}$ \\ Cristiane Maria Tonetto Godoy ${ }^{3}$
}

\begin{abstract}
RESUMO
Com os fenômenos do avanço tecnológico e da globalização, as áreas das Tecnologias de Informação e Comunicação (TICs) vêm sendo tratadas sob novas perspectivas, sendo uma das áreas que mais cresce mundialmente. Nesse sentido, o avanço na área de comunicação vem auxiliar na aproximação das pessoas que se encontram geograficamente distantes, o que antes poderia ser um processo oneroso, demorado ou até mesmo impossível. A distância não é mais sinônimo de estar longe dos entes queridos, ao contrário, a comunicação via internet ou celular é uma viabilidade real de manter contato constante com os membros da família, amigos e conhecidos que estão distantes, e ao afinal essa possibilidade se torna sinônimo de acalento, segurança e conforto, mesmo sendo virtualmente. Com essa possibilidade de comunicação e do estreitamento dos laços afetivos, que as TICs vêm colaborar com que os imigrantes permaneçam no país de destino, contribuindo com o desenvolvimento econômico, social e cultural no local em que estão inseridos. O presente artigo tem como objetivo realizar um ensaio teórico sobre as tecnologias de informação e comunicação como ferramentas de contribuição para o encurtamento das distâncias entre imigrantes haitianos residentes no Brasil e seus familiares e amigos. Cientes da complexidade do tema, esperamos contribuir com a discussão do papel das TICs como facilitadora à manutenção dos vínculos, proporcionando a permanência dos imigrantes e consequentemente como fomento para o desenvolvimento regional onde estão inseridos.
\end{abstract}

Palavras-chave: TICs. Haiti. Imigrantes. Desenvolvimento Regional. Comunicação.

\footnotetext{
${ }^{1}$ Mestranda do Programa de Pós-Graduação em Desenvolvimento Regional, Universidade Tecnológica Federal do Paraná, Pato Branco, Paraná. Brasil. E-mail: beatriz_Gustmann@hotmail.com

${ }^{2}$ Doutora em Educação, Professora do Programa de Pós-Graduação em Desenvolvimento Regional, Universidade Tecnológica Federal do Paraná, Pato Branco, Paraná. Brasil. E-mail: marial@utfpr.edu.br

${ }^{3}$ Doutora em Extensão Rural, Bolsista Pós-Doutorado, Programa de Pós-Graduação em Desenvolvimento Regional, Universidade Tecnológica Federal do Paraná, Pato Branco, Paraná. Brasil. E-mail: ctgextr@hotmail.com
}

DRd - Desenvolvimento Regional em debate (ISSNe 2237-9029)

v. 7, n. 2, p. 158-172, jul./dez. 2017. 


\title{
INFORMATION AND COMMUNICATION TECHNOLOGY AS A MECHANISM FOR MIGRATION: A STUDY OF HAITIANS IN BRAZIL
}

\begin{abstract}
With the phenomena of technological advancement and globalization, the areas of Information and Communication Technologies (ICTs) have been treated under new perspectives, being one of the fastest growing areas in the world. In this sense, advancement in the area of communication helps to bring people who are geographically distant, which could be an onerous, time-consuming or even impossible process. The distance is no longer synonymous with being away from loved ones, on the contrary, communication via internet or cell phone is a real viability of maintaining constant contact with family members, friends and acquaintances who are distant, and at last this possibility becomes synonymous with cherishing, security and comfort, even though it is virtually. With this possibility of communication and closer ties, ICTs will collaborate with immigrants to remain in the country of destination, contributing to the economic, social and cultural development in the place they are inserted. The present article aims to carry out a theoretical essay on information and communication technologies as tools to contribute to the shortening of distances between Haitian immigrants living in Brazil and their families and friends. Aware of the complexity of the theme, we hope to contribute to the discussion of the role of ICTs as a facilitator to the maintenance of the bonds, providing the permanence of the immigrants and consequently as a foment for the regional development where they are inserted.
\end{abstract}

Keywords: TICs. Haiti. Immigrants. Regional development. Communication.

\section{INTRODUÇÃO}

A migração, o ato da movimentação de pessoas de um lugar para outro, não é uma característica do atual século. Ao contrário, o ato de migrar esteve sempre presente na história humana, seja ela por motivos de alimentação, conquistas de novas terras, por guerras, para melhoria de vida, entre outros. Podemos dizer que historicamente é inerente ao ser humano estar em fluxo constante de deslocamento, entretanto, o que nos diferencia de outras épocas, é que a migração atualmente conta com um elemento que permite a aproximação do emigrante com a sua cultura de origem, o que é possível pelo avanço das tecnologias de informação e comunicação (TICs).

Corroborando, Branco (2006) afirma que vivemos em um período histórico revolucionário, denominado a "era da informação", e assim, nos deparamos com a possibilidade de interagirmos com vários instrumentos tecnológicos que têm como objetivo estabelecer novas formas de comunicações entre as pessoas e até mesmo das pessoas com coisas.

Pelo avanço das TICs, claramente a proximidade física e geográfica não são mais limitantes para a comunicação, a tecnologia se torna propulsora de novas modalidades de interações, dessa forma, a comunicação virtual e as telecomunicações se tornam um facilitador na aproximação das pessoas. No contexto das imigrações, o Brasil sempre foi um 
país acolhedor, sendo que na última década pudemos presenciar a expressiva vinda de imigrantes haitianos, isso devido a vários fatores, tais como: trabalho, estudos, instabilidade política e econômica, desastres ambientais, dentre outros.

No entanto, a locomoção do Haiti até o Brasil é um processo oneroso, o que faz com que apenas um membro da família migre, ficando o restante no país de origem. Assim, as tecnologias de informação e comunicação se tornam um auxílio na mitigação da distância e do sentimento do afastamento, bem como, é uma ferramenta importante para o desenvolvimento local, já que esses imigrantes vêm colaborar com a sua força de trabalho e no de consumo de bens e serviços.

As TICs favorecem a vicinalidade com familiares, bem como a proximidade com a cultura, os costumes, as músicas, entre outros, possibilitando desfrutar e aliviar um pouco a saudade do país de origem. Para os autores Lópes e Villamar (2000, p. 159), "[...] é evidente que a imigração implica na separação física do núcleo familiar, porém não necessariamente significa a ruptura das relações familiares de dependência afetiva".

O presente trabalho teve como objetivo refletir sobre a importância de tecnologias de informação e comunicação na permanência do imigrante haitiano no país, tendo como metodologia escolhida o levantamento bibliográfico, constituindo assim um estudo de base teórica. Para atender essa proposta buscamos em artigos em periódicos, dissertações, teses e trabalhos apresentados em eventos nacionais, estudos que refletissem e contribuíssem sobre as TICs e a migração haitiana.

Dessa forma, construímos a estrutura desse trabalho com base nas conceituações sobre tecnologia e tecnologia de informação e comunicação/TICs, a migração haitiana no Brasil e o papel das TICs para esses imigrantes.

\section{O QUE PODEMOS COMPREENDER SOBRE AS TECNOLOGIA E AS TECNOLOGIAS DE INFORMAÇÃO E COMUNICAÇÃO/TICS}

É inegável que os avanços tecnológicos têm conquistado espaço em tempo veloz no mundo globalizado, estabelecendo modificações profícuas e impactando os vários setores da sociedade. Nesse contexto, estamos vivendo em uma sociedade da informação, onde o acesso a livre à informação e ao conhecimento encontram-se disponíveis. Conceituarmos o que seria tecnologia ou até mesmo as tecnologias de informação e de comunicação, é desafiador, pois encontramos inúmeros conceitos e designações sobre os termos, bem como seus usos. O que pode ser visualizado na literatura é que são diversas dimensões em que o tema é dialogado, resultando assim em interpretações diversificadas.

Ao procurarmos sobre a origem da palavra tecnologia Peixoto, Brandão e Santos (2007), contribuem ao explicar:

\footnotetext{
A etimologia da palavra tecnologia é grega: téchne significa arte, destreza; e logos quer dizer palavra, fala. Adicionando o termo logos a téchne, percebemos que essa é a palavra (logos) que vem conferir significado ao fazer, à técnica. Então, tecnologia
} 
é um fazer com significado, um fazer pensando que tem uma intencionalidade (2007, p. 75).

Assim, podemos aferir que o termo tecnologia denota uma concepção de produção do conhecimento centrado na técnica, vindo auxiliar na construção do saber de forma coletiva e que possibilita intervenções, tendo o caráter intencional. Conforme Kawamura (1990), tecnologia traduz-se em conhecimento científico aplicados à produção e historicamente aglomerados pela apropriação sistemática de conhecimento intrínseco ao próprio exercício do trabalho. Para esse autor, a tecnologia presume coordenar seu uso na cadeia produtiva com a finalidade de suprir necessidades e favorecer o desenvolvimento econômico. Já o conceito de tecnologia para filósofo brasileiro Pinto (2005, p. 219), pode ser compreendido por diferentes categorias, para o autor a tecnologia "[...] tem que ser a teoria, a ciência, o estudo, a discussão da técnica, [...] as habilidades do fazer, as profissões e generalizadamente, os modos de produzir alguma coisa".

Dussel (1984) entende a tecnologia como forma de satisfazer as necessidades básicas do ser humano a partir das próprias realidades sociais vivenciadas, principalmente, nos países de terceiro mundo. $\mathrm{O}$ autor, salienta que a tecnologia vem permitindo ao homem uma maior produtividade, o que tem beneficiado ao capitalismo industrial. O sistema capitalista disposto e que é assistido pela tecnologia, é totalmente desfavorável ao ser humano, pois defende a emancipação do homem e, na perspectiva da disponibilidade da tecnologia atual, o homem acaba sendo mero escravo dos processos tecnológicos, pois ainda frisa que a tecnologia tem um caráter puramente econômico.

A compreensão de Gama (1986) sobre a tecnologia a partir dos preceitos do que não é tecnologia, denota a expansão dos horizontes de ponderações relativo ao tema. No entanto, a tecnologia abstém-se apenas de ser uma maneira instrumental ou estruturada como técnica e passa a ser considerada também nas suas proporções socioculturais que estão imbuídas do processo de produção. Contribuindo ainda com o tema, Gama (1986, p. 205-206) aborda:

A tecnologia não é um conjunto de técnicas, não é a forma como os homens constroem as coisas, não é o conjunto de ferramentas, máquinas, aparelhos ou dispositivos, quer mecânicos, quer eletrônicos, quer manuais quer automáticos; não é o conjunto de invenções, não é ciência aplicada, não é mercadoria e não deve ser confundida como o modo de produção capitalista.

É possível visualizar vários estudos que abordam o termo tecnologia como ferramenta ao capital e a produção, todavia, não podemos enxergar a tecnologia apenas como artefato econômico ou subordinado ao capital visando o lucro, devemos compreender que a tecnologia também é um instrumento de acesso a informação, de comunicação e de construção do conhecimento. Ao pensarmos nessa outra significação nos remetemos à tecnologia com o sentido do acesso a era digital e a comunicação, denominado pela literatura como as Tecnologias de Informação e Comunicação, ou simplesmente, as TICs.

Dentre as pesquisas sobre o que seriam as tecnologias de informação e comunicação encontramos em um site denominado InfoJovens ${ }^{4}$ a conceituação sobre o assunto de forma clara e resumida. Assim, o conceito trazido pela página é que as TICs devem ser compreendidas como um conjunto de recursos tecnológicos que visam proporcionar a

\footnotetext{
${ }^{4}$ INFOJOVENS. TICs. Disponível em: $<$ http://www.infojovem.org.br/infopedia/descubra-e-aprenda/tics/>. Acesso em: 07 de abr. 2017.
} 
comunicação, tendo como características principais, a agilidade, a horizontalidade e a possibilidade de manipulação do conteúdo da comunicação e informação mediante a digitalização e comunicação em redes, alicerçada basicamente na comunicação telefônica e virtual.

Contribuindo com a conceituação sobre as tecnologias de informação e comunicação Cruz (1997, p.160) aborda que "[...] é o conjunto de dispositivos individuais, como hardware, e software, telecomunicações ou qualquer outra tecnologia que faça parte ou gere tratamento da informação, ou ainda, que a contenha". Para Rezende (2005), a tecnologia da informação e comunicação deve ser compreendida como aquele conjunto de recursos computacionais que tem como função processar os dados e resultados, gerando assim informações e o conhecimento.

Nossa proposta para o presente artigo não é exaurir os conceitos existentes sobre as TICs e a própria tecnologia, mas buscar extrato na literatura que auxilie a compreensão dessas no contexto da migração e da comunicação globalizada e informatizada. Assim, ao perpassar as TICs no viés da comunicação virtual e telefônica, propiciadas principalmente através de celulares/smartphones, chats, vídeo chamadas, WhatsApp, entre outros, podemos afirmar que essas tecnologias possibilitam a manutenção da união, a reciprocidade e a interação das pessoas que estão distantes geograficamente. E ao transpormos para o fenômeno da migração, o uso das TICs (ou se preferimos denominar apenas de tecnologia) temos um aliado para esse imigrante, pois ele pode manter contato frequente com seus familiares, amigos e conhecidos, bem como com a sua cultura. Do mesmo modo, há uma efetividade maior de probabilidade que ele permaneça no país de destino e tende a se consolidar resultando na cooperação para o desenvolvimento regional.

\section{UM PEDAÇO DO HAITI NO BRASIL}

Para entender o papel que as TICs possuem nas migrações, torna-se importante compreender as características do imigrante no contexto do país de origem e o que o atraiu para o novo "lar", e é nesse tópico que pretendemos refletir o passado e o presente desse imigrante no Brasil. Para atender esse objetivo buscamos na literatura conhecer o Haiti historicamente, compreender a ligação dos haitianos com o Brasil e por fim dialogar sobre qual o papel das tecnologias de informação e comunicação para esse imigrante.

Podemos afirmar que os fluxos migratórios fazem parte da história do homem e o Brasil sempre esteve presente nas diversas correntes migratórias, abrigando uma diversidade de culturas na sua formação populacional. No entanto, em meados de 2010 o Brasil se insere no rol de destinos dos imigrantes haitianos, fato que até então não era perceptível a mobilidade deles para o nosso país. De acordo com Germani (1974), para que se possa compreender o processo de migração é necessário considerar não somente o que afasta ou atrai o imigrante a se deslocar, mas, é preciso entender as condições sociais, culturais e até mesmo subjetivas existentes tanto no país mãe, quanto no país de origem.

Pela contribuição acima, podemos afirmar que o processo de migração não é um fenômeno simples, de mobilidade apenas, ao contrário, ele é um processo complexo que 
denota vários condicionantes que levam o indivíduo a decidir migrar. Afinal, deixar os laços afetivos e a sua cultura e identidade para trás e iniciar uma nova fase em um país com hábitos diferentes não é um processo calmo e fácil, o que, muitas vezes, torna penosa a distância e a ambientação no novo lugar.

Para explicar a migração dos haitianos para o Brasil, se faz necessário primeiramente entender qual a situação vivida por esses indivíduos no Haiti. Em vista disso, encontramos durante a pesquisa de literatura um texto publicado por Moraes, Andrade e Mattos (2013) intitulado A imigração haitiana para o Brasil: causas e desafios, onde os autores fazem um estudo de grande relevância sobre toda a contextualização histórica da situação que o Haiti presenciou e presencia. Temos que basicamente a história dos haitianos sempre foi repleta de lutas e guerras, fragilizando assim a população que ali reside. Exemplificando essa afirmação, teremos que o Haiti foi colônia da França e que para conseguir sua independência foram treze anos de intensiva e sangrenta luta, conseguindo só no ano de 1804 se tornar a primeira república negra a nível mundial.

Barbosa (2015), em seu trabalho diz que a situação do Haiti se mostra de forma caótica, marcada por bloqueios econômicos por longo período, tentativas de ocupação pelos Estados Unidos, presidentes eleitos e posteriormente depostos, crises econômicas, além de quatro ciclones que atingiram o Haiti, levando a perdas econômicas da ordem de $15 \%$ do PIB. Corroborando Moraes, Andrade e Mattos (2013), apontam que o panorama atual do Haiti é composto por um sistema político desorganizado, uma economia em crise, a sensação de instabilidade de segurança, a disseminação do vírus da Síndrome da Imunodeficiência Adquirida/AIDS e de um surto de Cólera. É essa a situação que faz com os haitianos optem por migrarem para outros países, tais como, Canadá, EUA, França, Antilhas Francesas, República Dominicana e o Brasil.

Ainda, como se não bastasse os anos de ditadura, guerra civil e de violência, no ano de 2009 a população do Haiti foi atingida por três furacões, porém não haviam se recuperado dessa tragédia ambiental, quando em janeiro de 2010 houve um enorme terremoto chegando a magnitude de 7.3 na escala Richter. A capital, Porto Príncipe, teve estimado $80 \%$ das construções danificadas. Além do dano material estima-se que 230 mil haitianos morreram e 1,5 milhões ficaram desabrigados pelo terremoto (GIRALDI, 2012).

De acordo com a Organização das Nações Unidas (2015), o número de migrações internacionais contabilizou 244 milhões no ano de 2015 em território mundial, todavia, esse valor evidencia um aumento de $41 \%$ desde o ano 2000 de deslocamentos no mundo, incluindo quase 20 milhões de refugiados. Em relação ao Brasil especificamente Contiguiba (2014, p. 17) colabora ao dizer: "[...] o que chamou atenção em relação aos haitianos foi o fato de ser o primeiro movimento migratório desse país caribenho para o Brasil, somando-se a isso o fato de estar circunscrito a um momento de catástrofe pelo qual o Haiti passou em 2010".

Podemos afirmar que a projeção do Brasil como local de destino para os haitianos também foi auxiliado por três eventos que aconteceram no país, seriam eles, a Rio +20 no ano de 2012, a Copa do Mundo da Federação Internacional de Futebol/FIFA em 2014 e os Jogos Olímpicos no ano de 2016, que deu visibilidade do país para o mundo, além da atuação do Brasil como protagonista em ações no âmbito internacional, tal como a missão de paz no Haiti, o que vêm colaborando a difundir informações, tornando o país atrativo para aqueles 
que tem o propósito de migrar. Corroborando com a afirmativa, Patarra $(2012$, p. 13) destaca que:

[...] neste quadro, a presença do Brasil no Haiti, no comando da Missão das Nações Unidas para a Estabilização no Haiti - MINUSTAH, iniciada em 2004, foi fator de fundamental importância na inserção do país no quadro dos destinos procurados pelos haitianos que buscavam fugir da miséria e da desordem social.

Para Moraes, Andrade e Mattos (2013, p. 103),

\begin{abstract}
Além disso, o acolhimento dos primeiros imigrantes haitianos em território brasileiro, que foi realizado de forma amigável, diferentemente do que ocorreu em outros destinos onde a migração haitiana foi duramente repreendida, criou a imagem de um país acolhedor, servindo de motivação para a escolha do Brasil como possível novo lar.
\end{abstract}

Segundo os dados do Instituto Migrações e Direitos Humanos no Brasil (IMDH, 2016), nos anos de 2012 a 2016 foram registrados pela Polícia Federal um fluxo contínuo de mobilidade humana dos imigrantes haitianos até o Brasil. No ano de 2012 foram 4.278 mil haitianos que migraram, já no ano de 2016 esse valor subiu exponencialmente chegando na ordem de 42.026 mil haitianos chegando ao país. Esse dado da mobilidade humana do ano de 2016 é expressivo e demonstra que os fluxos migratórios tem se mantido constantes, principalmente no Brasil.

Sobretudo a distância, deixou de ser empecilho para mover-se de um território ao outro, conforme sintetiza Silva (2010, p. 21): “[...] a globalização é um processo no qual o encolhimento do mundo e as difusões culturais se tornam inevitáveis. Isto ocorre principalmente porque as distâncias se encurtam, a tecnologia se apressa e os reflexos das ações se tornam praticamente simultâneos".

A chegada dos imigrantes haitianos se dá principalmente através de duas regiões brasileiras: pelo município da Brasiléia no estado do Acre, fronteira com a Bolívia; e pela cidade de Tabatinga no Amazonas, fronteira com a Colômbia e o Peru. Ainda se tem rotas nos estados de Roraima, Mato Grosso e Amapá. Entretanto, ao analisar os diversos estudos sobre a migração e situação do imigrante haitiano no Brasil, é possível encontrar relatos e pesquisas que apontam que esse imigrante é visto como mão de obra barata, e muitas vezes se encontram em condições precárias no que tange à qualidade de vida, conforme afirmam Moraes, Andrade e Matos (2013, p. 106).

\footnotetext{
Salienta-se que os haitianos que procuram o Brasil para reconstruírem suas vidas, em sua maioria, possuem algum grau de qualificação profissional, portanto não são refugiados iletrados e sem preparo. Muitos deles possuem curso técnico, curso superior e falam até três idiomas, entre eles o espanhol e o francês. O mercado de trabalho brasileiro, entretanto, os exploram, principalmente aqueles que aqui estão em condição ilegal, como mão de obra barata e, não raramente, com poucos direitos trabalhistas empregados.
}

O fato é que os haitianos têm ajudado a suprir demanda de trabalho de baixa qualificação e não têm dificuldades de encontrar oportunidades em tal contexto (ALCANTARA, 2014). Ainda nesse sentido, Ribeiro (1991, p. 131) afirma que a "[...] finalidade é tratar o migrante como um objeto da relação de produção, desvinculado de sua terra natal, idioma, família e laços afetivos". O ato de emigrar no Haiti é realizado no intuito 
de ajudar as famílias com remessas financeiras, conforme destaca Silié (2003, p. 10) em sua percepção:

\begin{abstract}
Es notorio que el interés en ayudar a la familia es una de las motivaciones para emigrar, por parte de los haitianos, pues todos se refieren a ella, sea para explicar las causas de su salida, o de los viajes frecuentes a su país. Es indudable que el sueño de esos inmigrantes es ayudar a la familia. Esto mismo nos hace ver que ellos mantienen en un fuerte apego afectivo a su tierra; aunque también dicho apego es una de las razones para la decisión de traer sus familiares a República Dominicana, vista la situación de pobreza y desesperanza en su país ${ }^{5}$.
\end{abstract}

A estrutura familiar é muito simbólica para qualquer imigrante, pois remete ao significado de carinho, afeição e de aconchego, do mesmo modo que preservam o patriotismo pela sua terra natal, suas raízes e pela sua cultura. Para os haitianos a residência fixada no Brasil, seja ela por tempo determinado ou indeterminado, tem como significado a distância dos membros da família e da pátria, ou seja, não é apenas uma separação geográfica, ela tem conotação afetiva, física e identitária. Em relação à situação de precariedade de qualidade de vida e o sentimento de distanciamento do país mãe, o imigrante tem nas TICs a oportunidade de criar vínculo e fortalecer os contatos com familiares e amigos que estão distantes. Com efeito, permite uma conexão constante com a cultura nativa, por exemplo, a linguagem, dialogando no dialeto "crioulo" que é língua materna do Haiti.

Da mesma forma, é necessário considerar que estadia dos imigrantes no país de destino pode contribuir para o desenvolvimento da região em que estão estabelecidos.

\title{
4 A TECNOLOGIA (TICS) APROXIMANDO QUEM PARTIU DE QUEM FICOU
}

A implantação das tecnologias de informação e comunicação no cenário social está cada vez mais acelerado e crescente, tendo mudanças significativas em um curto espaço de tempo. Nesse sentido, surgem estudos que coadunam com os benefícios da expansão da tecnologia e outros apontam que essas mudanças evidenciam uma ruptura de ideais sociais, culturais, econômicas e políticas. Para tanto, não se pode negar que as TICs contribuíram significativamente para a evolução dos mais diversos segmentos de mercado na sociedade, para a comunicação ágil e eficaz, dispondo de várias ferramentas para serem utilizadas na informação e comunicação em tempo real.

A tecnologia tem a capacidade de modificar a sociedade. Para Primo (1997), ela viabiliza a interação e a criação de grupos de pessoas mesmo sem proximidades físicas, permitindo o contato com os entes queridos de forma frequente, amenizando a distância existente. Para Marcondes (2001, p. 110), a tecnologia é parte integrante de um espaço de troca de sensações, informações e vivências com o outro, sendo atualmente realizada por meio de máquinas eletrônicas e aparelhos. O autor frisa que "[...] as tecnologias tentam

\footnotetext{
${ }^{5}$ Tradução livre: É notório que o interesse em ajudar a família é uma das motivações para emigrar, por parte dos haitianos, pois todos se referem a isso, seja para explicar as causas de sua saída, ou das viagens frequentes a seu país. É indubitável que o sonho desses imigrantes é ajudar a família. Isso mesmo nos faz ver que eles mantêm um forte apego afetivo a sua terra; no obstante também dito apego é uma das razões para trazer seus familiares à República Dominicana, vista a situação de pobreza e desesperança em seu país.
} 
artificialmente reagregar um mundo de contatos humanos que na prática já está totalmente rarefeito, pulverizado".

O ser humano não vive isolado, ele necessita da interação com outras pessoas, no entanto, a mobilidade humana tem se tornado intensa e contínua, ultrapassando fronteiras. Nesse sentido, as TICs facilitam o contato e a interação com familiares e demais pessoas através da rede social, rompendo a lógica fronteiriça. Assim, o processo de virtualização da comunicação e da própria ação humana é potencializada na medida em que se institui um espaço sustentado pelas tecnologias digitais de rede, rompendo com quaisquer espaços-tempo e conectando os sujeitos no ciberespaço (MELLO, TEIXEIRA, 2012).

A questão da saudade e da solidão que os imigrantes haitianos sentem ao lembrar de familiares e da sua pátria, pode ser demonstrada no trecho a seguir:

\begin{abstract}
Estou aqui desde 2012, tenho muitas saudades do meu pai, minha mãe, esposa e filho. Se eu tivesse trabalho no Haiti, eu não teria saído de lá, não, pois o Haiti é um país que eu amo muito. Eu não me acostumei, tenho saudades dos amigos. Da minha música, do mar. Quanto à alimentação, eu me adaptei no trabalho, aqui em casa, preparamos nossa comida haitiana, mas na empresa comi o que me era oferecido sem problemas (WILGENS SAINTE, 27 anos apud BARBOSA, 2015, p. 123).
\end{abstract}

Ao lermos a declaração acima, podemos afirmar sem sombra de dúvidas, que um dos elementos da migração haitiana está justamente na questão de insegurança e crise que o país vive atualmente, fazendo com que seus cidadãos procurem em outras regiões a segurança e trabalho. Ainda, ao refletirmos sobre a declaração podemos aferir que o sentimento de saudade, da falta da família é presente no cotidiano desses imigrantes, bem como as dificuldades encontradas por estarem em uma nova cultura. Para Santos (2010) pode ser observado que o elo com a família é uma simbologia expressiva para os imigrantes haitianos, já que a maioria das pesquisas apontam que os haitianos fazem menção à família com sentimentos de afeto, carinho, amor e apoio, o que fica explícito em seus semblantes. A unidade de socialização, bem como a família, é responsável pelo treinamento dos indivíduos em atitudes, valores e reponsabilidades, ou seja, os orienta a ter um comportamento culturalmente apropriado ao seu meio social.

Nesse contexto, o fator preponderante do poder "comunicar-se" com os familiares e amigos pode ser um fator que atenue a sensação de solidão, frustação e desânimo que possa acometer os imigrantes, haja vista que quando chegam no Brasil enfrentam muitas dificuldades, tais como, a língua, a moradia, o trabalho, o acesso aos serviços de educação e saúde. Por outro lado, a interação e comunicação com a família de maneira permanente tende a contribuir com a permanência do imigrante haitiano no país de destino, já que a proximidade com a família consiste em ser benéfico para superar as adversidades diárias.

Assim, sobre o consumo midiático pelos imigrantes haitianos para manter contato com familiares que estão no Haiti, Barbosa (2015, p. 36), afirma:

A grande maioria dos haitianos tem acesso à internet e a redes sociais. Comunicamse, diariamente, com seus familiares no Haiti. Os avanços tecnológicos, sobre tudo do meio de transporte e das tecnologias de comunicação e informação, atuam na reconfiguração do fenômeno das migrações, com a dinamização dos processos de interculturalidade e transnacionalismo.

DRd - Desenvolvimento Regional em debate (ISSNe 2237-9029) 
Para os imigrantes haitianos é essencial o contato com os familiares e essa frequência na comunicação, mesmo sendo virtual, tende a ser decisivo para a permanência deles no Brasil. O trabalho como fator principal da migração tenciona como suporte para o desenvolvimento econômico e social da região onde estão inseridos.

Blanco (2006, p. 56) assinala que "[...] las distancias físicas se acortan, los movimientos se multiplican y el contacto virtual con los otros se hace posible en cualquier parte del mundo"6. Logo, as TICs são ferramentas que oportunizam a aproximação das pessoas que estão distantes, ajudando na ausência física, além de desempenhar papel de mediação e aproximação, o que minimiza a saudade e o distanciamento.

Também contempla outros mecanismos nos meios de comunicação virtuais que podem expressar sentimentos, por exemplo, o uso comum de "emotions" representando expressões faciais de emoção ou de qualquer outro sentimento e ato. De fato, são recursos que tendem a promover a aproximação e contato permanente com familiares, que pela questão de distância e investimento financeiro inviabiliza o contato pessoal ou a vinda desses para o Brasil. O cientista americano Negroponte (2000, p. 153) já previa as grandes mudanças na sociedade quando afirmava que “[...] a era da pós-informação e comunicação está removendo barreiras geográficas. A vida digital exigirá cada vez menos que você esteja num determinado lugar em determinada hora".

Nesse contexto, os relacionamentos na era digital tem se intensificado, não só no âmbito familiar, foco da presente investigação, mas também, nas relações de trabalho, nas reuniões, ambientes organizacionais, áreas educacionais, seja em tempo real através de mensagens, por áudio ou nas mais diversificadas formas. Como enfatiza Castells (1999, p. 419) “[...] o desenvolvimento da comunicação eletrônica e dos sistemas de informação propicia uma crescente dissociação entre a proximidade espacial e o desempenho das funções rotineiras". Portanto, a tecnologia e suas formas de comunicação e interação facilitam a mobilidade dos indivíduos e o permanente convívio digital.

Ainda para corroborar:

\begin{abstract}
A partir sobretudo do século XIX, a invenção do telégrafo, do telefone e o crescente avanço na área das transmissões foram, lenta mas progressivamente, mostrando as possibilidades dos dispositivos técnicos transcenderem, com limitações, a barreira do espaço, permitindo ao ser humano criar formas alternativas de manter ou criar relações (ANTUNES; CASTRO; MEALHA; 2001, p. 02).
\end{abstract}

O desenvolvimento tecnológico contribuiu sobremaneira com a conservação das relações de longa distância, desfazendo com o modelo de trocas comunicacionais que ocorriam, condicionado a estrutura do espaço físico, restringindo apenas ao local. Além do encurtamento de distância das relações pessoais que as TICs oferecem, igualmente fomentam o avivamento da cultura de seu país de origem, mantendo uma conexão, o que não deixa cair em desuso ou no esquecimento as suas raízes. Nas concepções de Yeoh, Huang e Lam (2005), Bryceson e Vourela (2002) e Baldassar (2007), as novas tecnologias de informação, comunicação e transportes permitem às famílias transnacionais estarem sempre conectados graças à internet, e-mails, telefonemas, mensagens por meio de redes sociais, permitindo aos membros da família "estarem juntos" em todos os momentos.

\footnotetext{
${ }^{6}$ Tradução livre: [...] as distâncias físicas se reduzem, os movimentos se multiplicam e o contato virtual com os outros se faz possível em qualquer parte do mundo.
}

DRd - Desenvolvimento Regional em debate (ISSNe 2237-9029)

v. 7, n. 2, p. 158-172, jul./dez. 2017. 
Sob outra perspectiva, é importante fazer menção à tecnologia como fonte de permanência dos imigrantes haitianos no Brasil, pois mantendo contato constante com os familiares, eles sentem que são apoiados minimizando a saudade e a distância. Deste modo, tendem a permanecer por um longo período no país, contribuindo para o desenvolvimento, não só a partir da venda da força de trabalho, mas também pelo consumo de bens e serviços que resultam em maior fluxo das transações comerciais. Em sua interlocução Simon (2015) imigrante haitiano que atua junto ao Centro de Referência e Assistência Social/CRAS, em Lajeado estado do Rio Grande do Sul, destaca que a perspectiva dos imigrantes no país é pela busca de melhores condições de vida através do trabalho e também no intuito de contribuir para o desenvolvimento do Brasil. Assim:

[...] o trabalho é um objetivo comum, porque trabalhar é liberdade. Não podemos negar que em nosso país a taxa de desemprego é muito alta, mas muitos querem trabalhar e estudar ao mesmo tempo para ter uma vida melhor. [...] podemos ajudar o Brasil a crescer, não apenas servindo com mão de obra mais braçal, mas também através de um trabalho profissional (SIMON, 2015, p. 359).

Portanto, pode ser observado que as tecnologias de informação e comunicação contribuem de forma significativa para a permanência dos imigrantes haitianos em território brasileiro, pelo alcance e aproximação dos familiares e por sustentar ativamente as questões inerentes à cultura do Haiti e que não se extingue pela aculturação do local de destino. A presença do imigrante faz com aconteça uma troca de cultura e saberes com os brasileiros.

Klagsbrunn (1996, p. 33), aponta que a "[...] migração de trabalhadores para os países industrializados, relata situações históricas que indicam que essa circunstância é cíclica e que tem relação direta com o desenvolvimento econômico dos países e regiões em que estão estabelecidos". Assim, a colaboração para o desenvolvimento regional pode ser constatada pelos aspectos econômicos, sociais e culturais e que também são fruto do auxílio de imigrantes (portugueses, italianos, japoneses, alemães) que vieram para cá e aqui foram protagonistas do desenvolvimento, o que não difere da situação de migração dos haitianos.

Como salienta Hein De Haas (2009, apud BRZOZOWSKI, 2012) a migração deve ser analisada como um processo naturalmente conectado e constituído de um processo mais amplo, ou seja, do desenvolvimento na sua dimensão econômica. Portanto, é notório que as imigrações ocasionem o desenvolvimento regional, podendo ser de maior ou menor volume, já que a migração é um fenômeno que está correlacionado com o desenvolvimento, bastando compreender o processo que se apresenta.

Contudo, para que o desenvolvimento ocorra se faz necessário um somatório de esforços e um dos pilares fundamentais para isso é o papel da tecnologia como ferramenta que impulsiona essa dinâmica. Ela tem como função estabelecer a comunicação e o vínculo pessoal para o imigrante, o que vem a permitir a sua contribuição social e econômica, bem como a permanência desse haitiano no país.

Ao final dessa breve reflexão, podemos aferir que as tecnologias de informação e comunicação/TICs, além do seu uso em empresas, engenharias, economia, áreas de educação, dentre outros, também, é um instrumento de suma importância no movimento da mobilidade humana, ou simplesmente nas migrações. As TICs possibilitam o contato com entes queridos em tempo real, de forma rápida e barata, ajudando a reduzir o sentimento de solidão, bem 
como, permite o permanente contato com a cultura mãe, o que vem colaborar com a permanência do imigrante no país e, consequentemente, com o desenvolvimento regional.

\section{CONSIDERAÇÕES FINAIS}

Longe de esgotarmos o assunto sobre as tecnologias de informação e comunicação e os seus múltiplos usos, concluímos que as TICs proporcionam o estreitamento das relações familiares, mesmo sendo à distância. O constante contato, além de sustentar o elo do núcleo familiar, também viabiliza o contato com a respectiva cultura minimizando os impactos da nova cultura em que ele está inserido.

A mobilidade humana se configura como contínua na esfera mundial. Desse modo, as renúncias de proximidade com os membros familiares se tornam inevitáveis. Diante deste contexto. As TICs são úteis para auxiliar o contato permanente com as pessoas que ficaram no país de origem, sejam por meio das redes sociais, mensagens, WhatsApp, ligações, entre outros, com o que é possível manter o convívio rotineiro e amenizar a saudades de familiares, bem como da terra natal.

Como evidenciam Bryceson e Vuorela (2002), antes da separação geográfica e da ausência da proximidade com a família, se constrói como comunidade imaginada, o que implica esforços continuados de seus membros (tanto aqueles que migraram como que ficam para trás) para manter os vínculos. A primordialidade é manter mecanismos que viabilizem o contanto permanente para reforçar, zelar e estabelecer liames com parentes e o círculo de amigos e conhecidos.

Na lógica de encurtar distâncias e manter vivas as relações familiares, a tecnologia constitui-se como ferramenta imprescindível nessa conexão. $O$ ser humano não vive sozinho, existe a necessidade da socialização e interação com outras pessoas, seja qual for o grau de proximidade. Porém, o ato de emigrar da terra natal e se ver em outro território totalmente distinto do habitual é uma prática muito desafiadora e de enfrentamento das adversidades. Deste modo, o contato familiar é vital, uma vez que podem compartilhar dores, alegrias, risos e choros, promovendo a redução da saudade. Consideramos que os novos espaços de comunicação existentes, alicerçados na tecnologia, não são oposição aos espaços físicos e sim um prolongamento e complemento destes, mantendo entre si uma estreita interação, bem como, resultam em um elemento de auxílio à permanência dos imigrantes, auxiliando na oferta de mão de obra e na dinamização do comércio e serviços na região onde estão inseridos, promovendo o desenvolvimento regional.

$\mathrm{O}$ ato de migrar configura-se como um direito humano, assim aqueles que sentem necessidade de deslocamentos a outros países não migram por qualquer razão. Na maioria das vezes, é pela busca de melhores condições e qualidade de vida. Assim, também trarão contribuição significativa para a promoção do desenvolvimento seja na escala regional, local e até mesmo nacional. É necessário mencionar que o imigrante não pode ser visto apenas como "fornecedor de mão de obra" disponível, que pode ser descartada quando não for mais útil ao mercado de trabalho, mas devemos perceber e conceber os imigrantes como produtores de riquezas simbólicas e não apenas materiais. 
Cientes que a temática não se esgota nesse trabalho de reflexão, recomendamos que mais estudos sejam realizados para compreender as dinâmicas da migração e as tecnologias de informação e comunicação e a sua importância para a migração, bem como, para o desenvolvimento regional, sendo necessário para isso a utilização e análise de determinadas variáveis, tanto materiais como imateriais.

\section{REFERÊNCIAS}

ALCANTARA, P. I. de M. Novas fronteiras: um olhar sobre a imigração haitiana para o Brasil. 2014. 117 f. Dissertação (Mestrado em Estudos Comparados sobre as Américas) Universidade de Brasília (UnB). Brasília: UnB, 2014.

ANTUNES, M. J; CASTRO, E. A.; MEALHA, O. Tecnologia da comunicação e informação na reconfiguração das redes de relações dos sujeitos. Biblioteca on-line de Ciências da Comunicação. 2001. Disponível em: < http://bocc.ufp.pt/pag/antunes-maria-joaoreconfiguracao-redes.pdf $>$. Acesso em: 23 out. 2017.

BALDASSAR, L. Transnational families and the provision of moral and emotional support: the relationship between truth and distance. Identities: global studies in culture and power, v. 14 , p. $385-409$, oct. 2007 ,

BARBOSA, L. S. Imigrantes haitianos no Rio Grande do Sul: uma etnografia de sua inserção no contexto sociocultural brasileiro. 201 f. 2015. Dissertação (Mestrado em Ciências Sociais) - Universidade Federal de Santa Maria. Santa Maria/RS: UFSM, 2015.

BLANCO, C. Migraciones: nuevas movilidades en un mundo en movimiento. Barcelona: Anthropos, 2006.

BRANCO, M. Software Livre e Desenvolvimento Social e Económico. In: CASTELLS, M.; CARDOSO, G. (Org.). A sociedade em rede: do conhecimento à ação política. Lisboa: Imprensa Nacional/Casa da Moeda, 2006, p. 227-235.

BRYCESON, D.; VUORELA, U. The transnational family: New European Frontiers and Global Networks. Cross-Cultural Perspectives on Women. Oxford: Berg, 2002.

BRZOZOWSKI, J. Migração internacional e desenvolvimento econômico. Estudos avançados, v. 26, n. 75, p. 137-156, 2012.

CASTELLS, M. A era da informação: economia, sociedade e cultura. São Paulo: Paz e Terra, 1999.

COTINGUIBA, G. C. Imigração haitiana para o Brasil: a relação entre trabalho e processos migratórios. 2014. 154f. Dissertação (Mestrado em História e Estudos Culturais) Universidade Federal de Rondônia. Porto Velho/RO: UNIR, 2014.

CRUZ, T. Sistemas, organização \& métodos. São Paulo: Atlas, 1997. 
DUSSEL, E. Tecnologia y necessidades básicas.In: DUSSEL, E. Filosofia de la produción. Bogotá: Nvena América, 1984.

GAMA, R. A tecnologia e o trabalho na história. São Paulo: Nobel, 1986.

GERMANI, G. Sociologia da modernização: estudos teóricos, metodológicos e aplicados a América Latina. São Paulo: Mestre Jou, 1974.

GIRALDI, R. Saldo do terremoto no Haiti é de 220 mil mortos e 1,5 milhão de desabrigados. Brasília: Agência Brasil. Disponível em: <http://agenciabrasil.ebc.com.br/noticia/2011-0112/saldo-do-terremoto-no-haiti-e-de-220-mil-mortos-e-15-milhao-de-desabrigados $>$. Acesso em: 10 de abr. 2017.

IMDH (Instituto Migrações e Direitos Humanos). Haitianos no Brasil: Dados estatísticos, informações e uma recomendação. 2016. Disponível em:

$<\mathrm{ftp}$ //ftp.mtps.gov.br/portal/trabalhador/trabalhoestrangeiro/publicacoes/Haitianos_dados_PF _CNIg-Recomendacao_de_Registro.pdf>. Acesso em: 25 mar. 2017.

KAWAMURA, L. K. Novas tecnologias e educação. São Paulo: Ática, 1990.

KLAGSBRUNN, V. H. Globalização da economia mundial e mercado de trabalho: a emigração de brasileiros para os Estados Unidos e Japão. In: PATARRA, N. L.

(coordenação). Migrações internacionais: Herança XX, Agenda XXI. Campinas: FNUAP; São Paulo: Oficina Editorial, 1996, p. 33-48.

LÓPEZ, S. O; VILLAMAR, D. El proceso migratorio en el sur de Quito. Cartillas sobre migración, n. 7, Plan Migración, Comunicación y Desarrollo, 2004.

MARCONDES, C. F. Sociedade tecnológica. São Paulo: Scipione, 2001.

MELLO, E. de F. F.; TEIXEIRA, A. C. A interação social descrita por Vigotski e a sua possível ligação com a aprendizagem colaborativa através das tecnologias de rede. In: Seminário de Pesquisa em Educação da Região Sul/IX Anped Sul, Anais..., 2012.

MORAES, I. A. de; ANDRADE, C. A. A. de; MATTOS, B. R. B. A imigração haitiana para o Brasil: causas e desafios. Revista Conjuntura Austral, v. 4, n. 20, out/nov. 2013, p. 95114.

MORAIS, J. F. R. de. Filosofia da ciência e da Tecnologia: Introdução metodológica e crítica. 5. ed. Campinas: Papirus, 1988.

NAÇÕES UNIDAS (ONU). International Migration Report 2015. Disponível em:< http://www.un.org/en/development/desa/population/migration/publications/migrationreport/d ocs/MigrationReport2015.pdf $>$. Acesso em: 25 mar. 2017.

NEGROPONTE, N. A vida digital. 2.ed. São Paulo: Companhia das Letras, 2000.

O QUE SÃO AS TIC? Revista de Ciências da Educação, n. 3. Disponível em:

$<$ http://escolas.madeira-edu.pt/eb1pescondestavel/tabid/10852/Default.aspx $>$. Acesso em: 08 de abr. 2017. 
PATARRA, N. L. O Brasil: País de imigração? Revista E-Metropólis, a. 3, n. 9, p. 01-18, jun. 2012.

PEIXOTO, M. de A. P.; BRANDÃO, M. A. G.; SANTOS, G. Metacognição e Tecnologia Educacional Simbólica. Revista Brasileira de Educação Médica, Rio de Janeiro, v. 29, n. 1, p. 67-80, jan. 2007.

PINTO, A. V. O conceito de tecnologia. Rio de Janeiro: Contraponto, 2005. v. 1.

PRIMO, A. F. T. A emergência das comunidades virtuais. In: Intercom 1997 - XX Congresso Brasileiro de Ciências da Comunicação, 1997, Santos. Anais... Santos, 1997.

RIBEIRO, G. L. Empresas transnacionais: um grande projeto por dentro. São Paulo: Ed. Marco Zero/Anpocs, 1991.

REZENDE, D.A. Sistemas de informações organizacionais: guia prático para projetos em cursos de administração, contabilidade e informática. São Paulo: Atlas, 2005.

SANTOS, M. A. dos et al. Migração: uma revisão sobre algumas das principais teorias. Belo Horizonte: UFMG/Cedeplar, 2010.

SILIÉ, R. La nueva inmigración haitiana. Santo Domingo, República Dominicana: Flacso, 2003. Disponível em:< http://cerlac.info.yorku.ca/>. Acesso em: 25 mar. 2017.

SILVA, C. R. V. A influência da globalização nas manifestações culturais e o diálogo intercultural como uma genuína alternativa de respeito à diversidade e ao multiculturalismo. In: V Anuário brasileiro de direito internacional, v. 2, p. 19-35, 2010, Anais.... Disponível em:< http://www.corteidh.or.cr/tablas/r27209.pdf>. Acesso em: 28 mar. 2017.

SIMON, R. Processo imigratório dos haitianos no Brasil. In: REDIN, G.; MINCHOLA, L. A. B. Imigrantes no Brasil: proteção dos direitos humanos e perspectivas político-jurídicas. Curitiba: Juruá, 2015, p. 357-368.

YEOH, B.; HUANG, S.; LAM, T. Transnationalizing the Asian family: Imaginaries, intimacies and strategic intents. Global Networks, v. 5, n. 4, oct. 2005, p. 307-315.

Artigo recebido em: 03/09/2017

Artigo aprovado em: 16/10/2017 